\section{DISPOSITIVO SECURITARIO EN UN ESPACIO BARRIAL. LA PRÁCTICA POLICIAL DE LOS CONTROLES DE IDENTIDAD}

\author{
Sergio García García \\ Universidad Complutense de Madrid \\ Universidad de Castilla-La Mancha
}

\section{SECURITY APPARATUS IN A NEIGHBORHOOD SPACE. THE POLICE PRACTICE OF IDENTITY CHECKS}

\begin{abstract}
This article discusses the management of the security apparatus and its differential application to population taking as a paradigmatic case the identity controls conducted by the police in the public spaces. The security apparatus, understood as a set of imaginaries, architectures, discourses and practices which emphasize "citizen safety" as a key point, is marked by two logics: the logic of neo-liberal management and the professional culture of security agents. Although these two logics arise from very different civilizational projects, they come together in a space like Carabanchel -along with other forms of 'expertise'- to delineate the figure of the citizen and of the "non-citizen" based on the differential relation established between neighbors through a process of class-differentiation and racialization. Thus the migratory process, problematized by the media and by institutions, has become a special object of control and surveillance shaping the differences upon the basis of which 'legitimate' identities are reconstructed in the neighborhood ("good citizens"). This proposal will describe how both of these logics of 'security' work, building a guilty subject of the victim neighbourhood -the "foreigner"- through selective police identity checks in public spaces.
\end{abstract}

KEY WORDS: Security apparatus; neo-liberal logic; disciplinary culture; differential management; identity checks.

\section{INTRODUCCIÓN}

Es de sobra conocido el auge de la "inseguridad ciudadana" como temática legitimada en las agendas de los medios de comunicación y de la política profesional en los últimos años. Los ajustes neoliberales han generado un incesante crecimiento de las desigualdades sociales y el Estado vuelve progresivamente a adoptar caracteres liberales para garantizar, sobre todo, protección al derecho a la propiedad privada e incentivar la competencia como principio motor de lo social. Construyendo una "seguridad ciudadana" acorde con el concepto cada vez más restringido de ciudadano (propietario, contribuyente, consumidor,
RESUMEN: El presente artículo aborda el funcionamiento del dispositivo securitario y su aplicación diferencial sobre la población tomando como caso paradigmático los controles de identidad que efectúa la policía en los espacios comunes de un barrio de Madrid. El dispositivo securitario, entendido como el conjunto de imaginarios, arquitecturas, discursos y prácticas que sitúan en un lugar protagónico la llamada "seguridad ciudadana", está atravesado por dos lógicas: la de la gestión neoliberal y la de la cultura profesional de los agentes de seguridad. Aunque sendas lógicas partan de proyectos civilizatorios muy distintos entre sí, ambas cooperan en el espacio urbano para contribuir -junto con otros dispositivos expertos- a delinear la figura del ciudadano -así como la del "no ciudadano"- a partir de la relación diferencial que establecen con los distintos vecinos mediante procesos de enclasamiento y racialización. Es asi como el hecho migratorio, problematizado a nivel mediático e institucional, constituye un objeto especial de control y vigilancia que conforma la diferencia a partir de la cual se reconstruyen las identidades legítimas en el barrio ("ciudadanos de bien"). Observaremos cómo las dos lógicas del dispositivo securitario funcionan construyendo al sujeto culpable del barrio víctima, el "extranjero", mediante los controles de identidad que efectúa la policía en los espacios públicos.

PALABRAS CLAVE: Dispositivo securitario; lógica neoliberal; cultura disciplinaria; gestión diferencial; controles de identidad.

elector) prolifera la centralidad del dispositivo securitario y su aplicación especial a la población migrante.

Entendiendo por dispositivo securitario el conjunto de instituciones, arquitecturas, discursos y prácticas que configuran la "seguridad ciudadana" como uno de los problemas político-culturales fundamentales de nuestro tiempo a nivel glocal, cabe señalar que en el mismo confluyen distintas lógicas culturales aparentemente contradictorias -desde las disciplinarias a las neoliberales- que, sin embargo, cooperan para dar lugar a un creciente control social "de arriba hacia abajo". Políticos profesionales, juristas, periodistas, portavoces policiales, etc., contribuyen hoy a 
generar un estado de opinión favorable al endurecimiento penal y a las medidas policiales, así como a crear un continuo estado de emergencia que recuerda que la solución a la incertidumbre es la cesión de una porción de autonomía a ciertos poderes políticos y expertos. A través de la proliferación de pánicos morales, de prejuicios xenófobos, de prácticas residenciales segregadoras, etc., buena parte de la población de la ciudad parece haber ido incorporando, de algún modo, esta lógica securitaria. Uno de los ejes fundamentales sobre los cuales se está construyendo el dispositivo securitario lo constituye la recomposición postcolonial ${ }^{1}$ del binario identitario-nacional en el que "el extranjero" se coloca en el "lado malo" de la realidad y amenaza al "lado bueno" moral-nacional, especialmente en las noticias sobre "sucesos" y en buena parte de los discursos barriales sobre "lo social". El complejo mediático, entendido como el conjunto de discursos e imaginarios hegemónicos y mediatizados, no es un conjunto de representaciones procedentes exclusivamente de lugares de poder, sino que buena parte de la "ciudadanía" contribuye a construirlo y a generar opinión mediante, por ejemplo, sus intervenciones en los comentarios de las noticias en Internet 0 a través de la apropiación estratégica de los discursos de la inseguridad. Estos discursos, recolocados en otros contextos -como el barrial-, sirven al objetivo de autolegitimarse como "buenos" ciudadanos/vecinos o como "víctimas" en la competencia por recursos escasos ("se lo dan todo a los inmigrantes... y encima vienen y nos matan").

El dispositivo securitario no es, entonces, exclusivamente una política inducida desde arriba, sino que atraviesa toda la estructura social y todos sus cuerpos. Todo ocurre como si un enorme volumen de imágenes, discursos, conversaciones, prácticas, decisiones, etc., tanto en los medios de comunicación como en las interacciones cotidianas, contribuyesen a evitar el hecho de "estar juntos" y a atomizar el cuerpo social. El peligro de pérdida de privilegios por parte de quienes detentan el poder económico, político o técnico puede estar entre las causas sociales de la proliferación del dispositivo, pero lo cierto es que buena parte de la población -privilegiada y no privilegiada- se ha introducido en su lógica de manera activa por la vía de la necesidad de diferenciación social en la sociedad de consumo (Bauman, 2003). La inmigración ha constituido la "diferencia" construida oportunistamente para llenar de contenido la necesaria figura del otro en el problema identitario-securitario. Este es el clima de aceptabilidad social sobre el cual se producen los controles de identidad selectivos por parte de los miembros de las fuerzas de seguridad que se abordarán en el último apartado del presente artículo: controles diferenciales en los que confluyen la lógica de gestión neoliberal de la seguridad ciudadana y la cultura disciplinaria compartida por los agentes de policía y que constituyen la causa y el efecto de una creciente segregación en el seno del cuerpo social a partir de la criminalización de la población migrante, muy especialmente la que no tiene "papeles".

Las reflexiones que a continuación se presentan son el resultado del trabajo etnográfico realizado en dos fases entre 2005 y 2011 en el barrio de Carabanchel, situado en la periferia sur de la ciudad de Madrid. En todo este tiempo, he realizado un total de 57 entrevistas en profundidad, tanto individuales como grupales, distribuidas entre las múltiples posiciones sociales (gestores, trabajadores securitarios -que venden su fuerza de trabajo tanto en el mercado formal como informal-, vecinos, etc.) que abarcan la complejidad intrínseca a una lógica de gestión que basa buena parte de su eficacia en la implicación de muy distintos actores sociales. A ellas deben sumarse más de una decena de presentaciones públicas con personas de dentro y fuera del barrio, paseos y conversaciones con vecinos de todo tipo, así como múltiples sesiones de observación participante en los espacios públicos, semipúblicos y privados del distrito.

Carabanchel (y sus símbolos arquitectónicos encarnados en el lugar en el que antaño se erigía la cárcel que tomó para sí el nombre del barrio y que hoy ocupa, de forma nada casual, el Centro de Internamiento para Extranjeros) me ha ofrecido el escenario en el que espacializar el dispositivo securitario que opera hoy en día en nuestras ciudades. Sin embargo, conforme la investigación fue avanzando, las fronteras del barrio pronto se revelaron ajenas a una realidad que las desbordaba continuamente: según me fui adentrando en el enclave fue surgiendo la necesidad de salir del mismo, siguiendo los hilos de un dispositivo que atraviesa sus espacios comunes y privados, pero que va mucho más allá de él. De esta forma, la investigación dejó de ser, desde sus primeros momentos, una etnografía situada en un barrio para tomar una forma mucho más móvil y flexible, precisamente la misma que caracteriza a la lógica neoliberal de la "seguridad 
ciudadana". Comenzaré el presente artículo abordando las características del dispositivo securitario y las lógicas que lo atraviesan, para mostrar su materialización en la práctica de los controles de identidad por perfil sociofenotípico que se realizan en los espacios públicos del barrio ${ }^{2}$

\section{Gestión neoliberal de la "seguridad CIUDADANA"}

La alta legitimidad de los cuerpos de seguridad encuentra sus raíces en el populismo punitivo (OSPDH, 2005), el más eficaz cemento social entre las instituciones y las clases populares hoy en día. Existen en la actualidad pocos elementos, como la condición de "víctima" de la inseguridad real o potencial de la pequeña delincuencia, que permitan a las personas sentirse ciudadanas, lo cual convierte a la policia en un cuerpo profesional que contribuye a ciudadanizar -o todo lo contrario- a las personas con las que interviene ${ }^{3}$. El "derecho a la seguridad" parece haberse consolidado frente a la "seguridad de los derechos" (Baratta, 2001), si bien a nivel discursivo se ha querido adherir a la seguridad ciudadana conceptos como "libertad", "participación" o "transparencia". Esta resignificación de la intervención de las fuerzas de seguridad sobre el espacio social nos informa de un enfoque relativamente novedoso que hemos dado en llamar gestión neoliberal de la seguridad.

Bajo esta concepción, el funcionamiento de lo social debe ajustarse a las reglas del mercado. Para ello no se interviene sobre el mercado, sino sobre lo social para el mercado, organizándolo a la manera de empresa, fomentando la rivalidad y la competencia como palanca de deseo en el seno del cuerpo social. Así, no se buscaría reducir las desigualdades sino modularlas para convertirlas en estimulo de la competencia. Desigualdad y competencia se entienden, pues, como los principales motores de lo social (Lazzarato, 2008). Desde esta óptica, la gestión securitaria no busca eliminar las disfuncionalidades, sino detectarlas y mantenerlas a raya, conteniéndolas dentro de un desequilibrio sostenible.

Para ello la gestión neoliberal de la seguridad requiere de un conjunto de medidas muy diversas entre sí con un triple objetivo: en primer lugar gestionar y redistribuir los riesgos -que se asume que no van a ser eliminados en un contexto de crecientes desigualdades- mediante las técnicas de la diferenciación y la prevención situacional en segundo lugar, crear el problema de la "inseguridad ciudadana" en el imaginario social y establecer, así, una demanda que constituirá el sentido del monopolio estatal (o privado) de la violencia física y dejará abonado un nuevo campo para los negocios privados y la centralización de poder político; y en tercer y último lugar, capitalizar dicho campo, el de la "inseguridad ciudadana", con el fin de que se transforme en fuente de recursos y de poder (dinero votos, reconocimiento).

En cuanto al primer objetivo, frente a una concepción centrada durante el fordismo en el "orden público" -persecución, castigo y corrección del delincuente-, el paradigma de la "seguridad ciudadana" parte de una gestión que se inscribe en la propia complejidad social, asumiendo pequeños fenómenos disruptivos siempre y cuando éstos no supongan una amenaza al orden social. No se trata, por tanto, de evitar el mal, sino de minimizar dicha amenaza, para lo cual la gestión securitaria parte del cálculo y la gestión del riesgo. A través de un conjunto de operaciones, no se busca tanto la corrección de conductas individuales cuanto la incidencia sobre aquellos "factores sociales" que podrian desencadenar el riesgo. Así, un "problema de inseguridad" (desde un brote de robos en una zona a la práctica del botellón) puede abordarse a través de un repertorio de acciones, como el incremento de la presencia policial, la implementación de programas especiales de intervención social o la elaboración de campañas de sensibilización. De este modo, podemos encontrar incoherencia en las medidas tomadas para atajar un problema, lo cual suele generar la sensación de gestión "chapucera" (una semana se indica una cosa y a la semana siguiente la contraria), tanto en la opinión pública como entre los propios agentes de seguridad. Sin embargo, si comenzamos a pensar en este tipo de gestión como una serie de respuestas fragmentadas que no intentan acabar con el problema en sí, sino redistribuir los riesgos que conlleva -partiendo de la noción de que los problemas se manejan, no se solucionan, ya que tienen una existencia y un movimiento natural (Foucault 2008)-, estaremos en mejor disposición de entender la gestión securitaria. El objetivo no es utópico ("acabar con la delincuencia"), sino pragmático ("gestionarla"). Así lo explicaba la vocal del partido gobernante en el Ayunta- 
miento de Madrid en el Consejo de Seguridad del distrito de Carabanchel:

"Siendo conscientes de que siguen cometiéndose delitos en todos los órdenes, sin embargo (...) tengo que destacar el trabajo y enorme esfuerzo de los cuerpos de seguridad (...). Los accidentes no van a desaparecer; la delincuencia no va a desaparecer (...). El compromiso es intentar hacer lo más posible con los medios de que disponemos (...). Hacia la utopía tenemos que tender, pero que no podemos reducir a cero lo que es imposible. Delitos va a haber siempre. Vamos a intentar controlarlo lo mejor posible y esa es la línea que estamos pretendiendo seguir en Policía Municipal."

(Vocal del Partido Popular en el Consejo de Seguridad distrital de diciembre de 2009)

El cálculo de costes y beneficios de la gestión tiene como resultado la instrumentalización de la técnica de la diferenciación social de los cuerpos en categorias identitarias. Esta diferenciación no es original, sino que procede de una cultura disciplinaria en la que a los cuerpos se les adhieren categorias de sujetos para dar lugar a individuos. Sin embargo, en la gestión biopolítica de la realidad, donde no se incide tanto en los individuos como en las poblaciones, estas diferencias son usadas, más que nunca, para establecer jerarquías y competencia entre ellas. Dicha competencia, propia de un orden cultural neoliberal, reproduce en el seno del cuerpo social las relaciones empresariales que se espera supongan el motor del desarrollo de la sociedad en su conjunto (Foucault, 2007a). No sólo se respeta la diferencia, sino que se potencia (Ávila y Malo, 2007). El objetivo no es la asimilación de los individuos a una disciplina común, sino la división de la población en grupos escalonadamente diferenciados. La diferencia a la hora de otorgar derechos en función de la situación administrativa (basada en tener DNI, NIE o estar en situación "irregular") no se apoya -al menos aparentemente- sobre esencias basadas en el origen, el fenotipo, la lengua, etc. Desde esta perspectiva, el pensamiento racista y etnocentrista no forma parte del programa neoliberal del Estado. Sin embargo, esta jerarquía de situaciones administrativas -que atraviesa otras jerarquías tradicionales basadas en aspectos de clase y de género- tiene su correlato en una aplicación diferencial de la "seguridad ciudadana" en función del grado de ciudadanía. Son finalmente los agentes a pie de calle quienes aplican, con los "criterios" de los que disponen -criterios finalmente visuales-culturales-, las medidas de persecución de delincuentes e identificación preventiva. Sin este saber a la hora de diferenciar (para no "parar" a todo el mundo y así no entorpecer el funcionamiento social del barrio) entre los "malos" y los "buenos", no se podrian aplicar las políticas de gestión neoliberal del espacio público.

Pero desde el punto de vista de la gestión securitaria, además de indicar a quién hay que mantener bajo vigilancia preventiva, la diferencia es un valor que debidamente reconocido puede facilitar el trabajo. Los nuevos saberes securitarios son incorporados por los propios profesionales, como en el caso de Roberto ${ }^{4}$, que narraba cómo en el centro de reforma de menores en el que trabajaba se les daba a los chicos originarios de Marruecos comida sin cerdo tras haber vivido algunos conflictos por ese motivo:

"iFíjate, con el ramadán de los marroquies hemos tenido unas movidas! (...). Cuando empezó todo el rollo, los españoles no sabían mucho del marroquí, y menos del ramadán, entonces claro: comidas con chorizo, comidas al suelo, así [gesticula simulando tirar un plato al suelo], con la correspondiente historia. Tanto educadores como vigilantes marroquies, que han sido muy importantes, gente normalizada, más mayor, ha sido muy importante para enseñarnos a nosotros y para controlar el percal, porque realmente es que claro, llega un chaval que te está hablando, que quitando cuatro palabras que son las que sabe todo el mundo, las palabrotas de cualquier idioma, no sabes lo que te está diciendo -era bonito, claro, desde luego-, y comidas al suelo, cuchillos en medio, ¿sabes?, por haberse encontrado un cacho de chorizo en la boca (...). Ha mejorado pero por conocimiento nuestro, pero para que veas que al final nos estamos acoplando nosotros a su cultura en nuestras ciudades, en nuestro pais, cuando realmente deberian ser ellos los que deberían acoplarse, con su cultura, pero ellos a nosotros, no imponiendo."

(Roberto, 33 años, vigilante de seguridad)

Podemos observar cómo el conflicto se gestionó reconociendo la singularidad de los chicos marroquies para prevenir disturbios. Esta entrevista ilustra el tránsito de una lógica asimilacionista a otra centrada en la gestión de poblaciones encarnado en un vigilante cuya experien- 
cia profesional le ha ido enseñando a actuar con mayor pragmatismo. Roberto se rendía ante la evidencia y renunciaba a la propia cultura disciplinaria de origen ante la constatación de que resulta utópica. La externalización de los dispositivos de frontera (que sea Marruecos quien se encargue del control del tránsito a Europa) y su correlato en la creación de dispositivos de reforma de menores en suelo marroquí, acabó constituyéndose en el argumentario de este vigilante:

"Hombre, controlar la emigración desde el principio, regularizar a la gente que realmente valga la pena que esté aquí trabajando, y a los demás mandarlos a sus lugares de origen, obviamente (...). Incluso yo he oído alguna vez, con la gente extranjera, los chavales marroquies, que había tantos, que de 14 chavales que tenía (...), he llegado a tener 11 marroquies, tela, 11 marroquies, 2 vigilantes marroquies y 1 educador, o sea, imagínate, más de la mitad de la plantilla del centro era marroquí, o sea, esto ya es importante, el nivel que hay pues se estaba hablando de que España pagara en Marruecos centros de menores para hacerlos alli (...). Lo vería muy bien, porque aunque España aporte y ayude, estarian alli, aunque haya que mandar ayuda, alli, y se enseña a los marroquies a ser vigilantes y a estar en sus cárceles con su propia gente."

(Roberto, 33 años, vigilante de seguridad)

Aparte de la diferenciación, en la que "toma cuerpo" la gestión securitaria de la población, la segunda técnica que ha ido cobrando relevancia mediante la hiperpresencia de policía y de elementos securitarios en las calles, es la llamada prevención situacional, la cual no persigue acabar con el delito, sino redistribuirlo y mantenerlo bajo unos márgenes controlables. Ante la constatación de que el propio sistema socioeconómico no va a "integrar" a todas las personas en la "ciudadanía", se hace necesaria una gestión preventiva del excedente humano que colocará a colectivos enteros bajo sospecha (De Giorgi, 2006).

Pero el dispositivo securitario no se caracteriza únicamente por estar apegado a la realidad material, sino también por insistir en la producción de una realidad imaginaria: la "inseguridad ciudadana". Descartado el objetivo de "evitar el mal" y apostando por una gestión que produce en sí misma diferenciación y desigualdad -algo irrenunciable desde el punto de vista de la competencia como motor social-, el abordaje de lo social se hace tan complejo que requiere de la puesta en práctica de mecanismos de control muy finos que se inserten en todas y en cada una de las esferas de la vida cotidiana. De ello se deriva un creciente intervencionismo experto sobre distintas áreas relacionales conflictivas que anteriormente eran ajenas a la actuación policial. Progresivamente, la policía se convierte en necesaria y su actuación incide eficientemente en el campo de la llamada "inseguridad subjetiva". El cambio de enfoque de la lógica neoliberal no sólo implica, por tanto, un mayor espacio de intervención, sino una transformación en la concepción de las fuerzas de seguridad, que dejan de ser consideradas un elemento meramente represivo y se convierten en un servicio de protección ciudadana. Desde esta nueva perspectiva, las fuerzas de seguridad además de ver, deben ser vistas.

El fuerte crecimiento de la presencia policial en las calles ${ }^{5}$, muy superior al del número de habitantes, hay que compararlo con la tasa de criminalidad en la ciudad, que en el período 2003-2010 pasó de 94,7 a 90,5 delitos y faltas por cada 1.000 habitantes $^{6}$. Sin embargo, la seguridad no se gestiona sólo a partir del frío análisis de esos datos, sino a través del juego de interpretaciones sobre los mismos ${ }^{7}$. Estas estadisticas, más que informarnos objetivamente sobre lo que ocurre en las calles, producen la realidad que demanda la intervención de las fuerzas de seguridad. Las estadísticas policiales han sido fuertemente criticadas por sus sesgos: contabilizan lo que la policía ve, pero las gafas de los agentes son muy particulares y las órdenes de los responsables responden a demandas políticas concretas, como en el caso de los cupos de detención por países para los miembros del Cuerpo Nacional de Policía (CNP) ${ }^{8}$. Las distintas formas de medir la "inseguridad ciudadana" nos permiten deducir que más que los datos, es la presencia de la propia temática de la inseguridad ciudadana en los espacios de visibilidad (prensa, televisión, espacio público etc.) la que tiene efectos performativos. Así es como en distintas conversaciones he podido escuchar en boca de vecinos del barrio afirmaciones como "el noventa por ciento de los robos los hacen extranjeros". A pesar del interés que tendrian muchos en difundir este dato, es bastante improbable que ningún medio lo haya aportado por su elocuente falsedad estadística9. No es el cálculo matemático lo que guía a quienes se apropian de este tipo de informaciones, sino los efectos de verdad de su presencia 
visible. "Noventa por ciento" no significa un frío cálculo, y más cuando no se lo compara con otros, sino que es el instrumento lingüistico para problematizar un asunto, en este caso la presencia de población migrante en el barrio en el contexto de precariedad y competencia individualista por recursos escasos. Las cuentas, convertidas en cuentos (Ibáñez, 1985), producen la demanda en el imaginario: ¿pero cuál es la oferta?

El de la seguridad constituye un nicho de negocio relevante en el que se mercantilizan aspectos de la vida que antes eran gestionados por la propia población y se externaliza una parte de la gestión estatal securitaria ${ }^{10}$. El mercado, principio rector de lo social desde una perspectiva neoliberal, encuentra en lo securitario un campo sobre el que expandirse en el que emergen empresas y empleos precarios ${ }^{11}$. Pero además de la capitalización económica, el campo securitario produce una rentabilización política en forma de votos y legitimidad para la que es necesario traducir la inseguridad en datos y actuar una performance que dé muestras de eficacia ( $y$, cada vez más, de belleza en un proceso de asimilación entre lo bueno y lo limpio-bello). Este escaparate de la propia gestión consigue eliminar todos los restos corporales de la intervención policial ${ }^{12}$, de ahí que los propios agentes de policía se vean cada vez más inmersos en la lógica de codificación de todo su trabajo. Cada acción que realizan debe tener su reflejo en plantillas, bajo la amenaza de que no se les reconocerá su mérito 0 de que se les cargará con más trabajo ${ }^{13}$. Así es como esta lógica -al mismo tiempo de gestión y estética-, que responde a la necesidad de mostrar números acordes a las demandas, produce en ocasiones el efecto perverso de la producción de identificaciones, detenciones, registros, etc., sin que exista ningún acontecimiento concreto que motive su realización ${ }^{14}$. Un caso paradigmático es el de los "Latin King". Esta "banda latina" hizo correr ríos de tinta en el momento en que se comenzaba a problematizar la inmigración y a atribuírsele las causas de la inseguridad en Madrid a principios de la primera década del s. XXI. La intervención policial y judicial contra la banda fue el resultado de algunas muertes producidas por sus miembros, una de ellas de amplia resonancia mediática y acaecida en la Plaza Elíptica (Carabanchel) ${ }^{15}$. Tras acaparar la primera plana mediática, y con buena parte de sus componentes en prisión, comenzó un programa de intervención social ${ }^{16}$ que durante dos años mantuvo interlocución directa con los líderes del grupo. Una vez caída en el olvido la banda bajo los parámetros de la "alarma social", dejó de financiarse dicho programa y al poco tiempo reapareció la intervención policial para "descabezar" de nuevo al grupo y darle amplia difusión mediática. Según denuncian los propios coordinadores del programa de intervención, éste era el cuarto descabezamiento y todos los anteriores, lejos de prevenir los actos delictivos de "los Latin", no habían sino retroalimentado el prestigio como "malos" de sus miembros ${ }^{17}$. ¿Qué lógica podemos encontrar en este tipo de intervenciones, mucho más costosas a nivel de gestión económica y mucho menos "rentables" a nivel social? La respuesta podemos encontrarla en una gestión pública de la realidad que, lejos de proponerse la verdadera eliminación de la violencia, trata de administrarla de manera fragmentada para así capitalizarla. Más que una interpretación maquiavélica sobre un cerebro organizando un plan, quiero plantear que todo ocurre como si existiesen multitud de agentes dentro del Estado que tratan de atesorar los problemas de acuerdo a una lógica competitiva por el reconocimiento dando lugar a múltiples intervenciones, las cuales, eso sí, juegan en su conjunto a favor del sostenimiento del dispositivo securitario. A través de la intervención social se "tolera" la existencia de las bandas como grupo con sus "diferencias", lo cual permite mostrar a la opinión pública una respuesta cualificada y "tolerante"; a través de la respuesta policial se efectúa una demostración de fuerza mediática ("tolerancia cero con las bandas latinas") en la que se transmite que se actúa con "mano dura" contra el crimen: dos tendencias contradictorias que sin embargo hay que combinar hábilmente para escenificar en un contexto emergencialista que se actúa dando respuesta a la alarma social ${ }^{18}$.

Podemos imaginar entonces, que para los gestores, el significado de la inseguridad difiere del que le asigna el vecindario. En una ocasión consulté ingenuamente a Pérez ${ }^{19}$, uno de los responsables de la comisaría del CNP, si creía que había aumentado la inseguridad en Carabanchel. Refiriéndome a la "inseguridad" como experiencia subjetiva de los vecinos, mi pregunta, sin embargo, le remitió automáticamente a otra realidad: a su responsabilidad profesional como gestor. Adoptando una posición defensiva, relacionó directamente "seguridad" con "policía", y sacó a relucir una argumentación en favor de la labor de los profesionales, destacando la falta de medios y la falta de respaldo de los jueces. Pérez se vanagloriaba de los éxitos profesionales: "El tema de bandas lo tenemos todo controlado". Para él, 
los problemas de inseguridad existian, eran graves y estaban creciendo, pero no en su feudo: "Somos la tercera comisaría en eficacia (...). La gente colabora, la gente nos ve bien, porque ve que se están haciendo cosas"20.

En el Consejo de Seguridad del Distrito, los responsables políticos y policiales no cesaban de "vender" su propia actuación y de agradecer a los asistentes -miembros de entidades sociales del distrito- su presencia. El jefe de Policía Municipal en el distrito presentó a la audiencia el programa "Madrid seguro", el cual aúna "seguridad ciudadana" y "atención al ciudadano". Se trataba -ahora sí- de incidir en la "seguridad subjetiva" mediante una atención propia de los entornos comerciales. Los propios asistentes al Consejo eran situados en esa posición de clientes:

"En los cuatro primeros meses de 2009 se han incrementado un 55\% las intervenciones en agresiones y reyertas (7 reyertas por día). Se ha incrementado su intervención un $10 \%$ en delitos contra la propiedad. Las detenciones: 347 personas en esos primeros 4 meses del año. Se ha incrementado bastante en delitos contra la seguridad del tráfico. En robos y violencia doméstica también se ha incrementado mucho."

(Responsable de Policía Municipal en el Consejo de Seguridad Distrital, diciembre de 2009)

El responsable de policía nacional (CNP) insistía en el discurso de la escalada simétrica (crece el mal; crece la policía), manifestando que "se han incrementado un 16\% los robos con intimidación, así como el número de detenciones por ese motivo (un 115\%)"21. En el marco de una estetización de cara a cuidar la imagen ante un tipo de ciudadanos, los más legitimados, las instituciones securitarias han incorporado un discurso que incide sobre los aspectos subjetivos de la seguridad, reconociendo la importancia de la comunicación simbólica con la ciudadanía ${ }^{22}$. Pero no sólo las instituciones securitarias se embellecen. Los propios miembros de las fuerzas de seguridad han ido encarnando en sus cuerpos la transformación del modelo de policía inducido desde la gestión política. Podemos observar una suerte de "cristianoronalidización" de la policia, una especie de embellecimiento "metrosexual" de los agentes consistente en sus nuevos trajes negros, sus cuerpos jóvenes y atléticos y sus potentes vehículos renovados ${ }^{23}$.

\section{TRABajadores Securitarios: Del lado malO AL LADO BUENO}

La lógica de la gestión neoliberal descrita en el anterior apartado funciona, en la práctica, de manera combinada con la cultura profesional de los trabajadores securitarios "a pie de calle", la cual parece adscribirse de manera fiel a una lógica disciplinaria y a sus consecuentes subjetividades $^{24}$. De ahi que, en ocasiones, los agentes muestren su repulsa hacia ciertas medidas y decisiones tomadas por instancias superiores bajo la lógica de la gestión. Para ellos, por ejemplo, el gobierno da "palos de ciego" en materia de extranjería, al tomar medidas aparentemente contradictorias, dando la sensación de des-gobierno ("habiendo dejado entrar a demasiados extranjeros") y pervierte su profesión al obligarles a hacer trabajos diferentes al de "perseguir delincuentes" (su vocación según el discurso), como realizar controles de identidad a personas con fenotipo extranjero.

En contextos sociales desfavorecidos en los que las oportunidades laborales y de reconocimiento escasean, una parte no desdeñable de sus figuras masculinas vende su fuerza de trabajo en la provisión de servicios securitarios -tanto en el mercado formal (militares, policías, vigilantes de seguridad privada, escoltas, etc.) como en el informal ("gitano cuidando obra", "machaca", "matón", etc.)- como una de las exiguas vías factibles de obtención de recursos económicos ${ }^{25}$. Así lo explicaba Ramón ${ }^{26}$, vigilante en un centro de servicios sociales:

"La gente que entra o es por necesidad (...), gente que se ha quedado en paro de otro sector que intentan entrar (...). Por regla general es gente que viene de barrios muy conflictivos y con pocos estudios (...). Yo soy un proletario duro y puro, vamos, vendo mi trabajo por un salario, vamos, y encima salario bajo (...). Si me sale un trabajo mejor que este, que gane más dinero, como proletario vendo mi trabajo."

(Ramón, 44 años, vigilante de seguridad)

Es el caso, también, de Javi, autodefinido como "escolta de un famosote", cuyo cuerpo trabajado en el gimnasio se acompañaba del lenguaje masculinista procedente de sus años de "malote"27. Y es que existe una continuidad entre cierto lenguaje hipermasculino y "barriobajero" y el que emplean en su trabajo muchos profesionales de la 
seguridad cuando abandonan el vocabulario eufemístico profesional (algo que ocurre a menudo cuando crece la tensión en sus intervenciones).

Una vez dentro, y a medida que se asciende en la escala profesional que va desde la informalidad (vigilantes ilegales de obra o porteros de discoteca) a la estabilidad laboral (policías públicos), pasando por la precariedad (vigilantes de seguridad), el propio ejercicio de la profesión funciona como forma de diferenciación -"lado bueno"- frente a aquellos que encarnan la desviación de la normalidad -"lado malo"- en un mundo social compartido. Esta afirmación identitaria se constituye en coherencia con una cosmovisión disciplinaria que contiene una bipolaridad de posiciones enfrentadas (aunque fácilmente intercambiables) y que es la que prevalece en el seno de la cultura profesional de los cuerpos de seguridad.

Este mismo gradiente (de la informalidad a la estabilidad) es el que determina los distintos niveles de identificación con su labor a la hora de intervenir sobre el "lado malo". Así, los argumentos que suelen manejar los vigilantes de seguridad del metro a la hora de actuar frente a conductas prohibidas en las instalaciones ("top manta", reparto de panfletos o publicidad, etc.) discurren por senderos relativos a cierta conciencia de clase ("luego va a ser la mujer de la limpieza a quien le toque trabajar doble") y de subalternidad ("su trabajo choca con el mío (...), a mí me da igual que venda CDs, lo que digo es que las cámaras me están grabando y si yo le dejo ponerse, a quien se le cae el pelo es a mí") ${ }^{28}$. Al contrario que muchos policías y otras figuras de autoridad, no se sienten legitimados para indicar a los demás cómo deben orientar su conducta, sino que "cumplen órdenes". Sin embargo, el empleo en las fuerzas de seguridad del Estado permite escapar de esa precariedad y dar el salto definitivo al "lado bueno", lo que se traduce también en una mayor identidad profesional y en un papel más activo a nivel disciplinario-moral. Un veterano miembro del CNP recorría su biografía carabanchelera de este modo:

"Entonces, mi padre es ebanista, estaba trabajando en una empresa y le dieron un piso ahí y vinimos a vivir ahí, y ahí me crié. Yo, fijate, ahi si te puedo hablar que era una zona que era muy marginal. Ahí empezó el mundo de la heroína, empezó, pues, en la época mía, y de toda la panda que éramos nosotros quedamos cuatro, uno es abogado, yo que soy policia y dos que están en fase terminal de SIDA por la heroina, los demás todos han muerto de lo mismo, jtodos! Es más, yo estuve, yo antes de venir a Carabanchel y antes de ascender a subinspector, estuve de oficial, y estuve en la Brigada (...), y allí me encontré a un compañero del colegio detenido. Alli estaban las dos partes (...). Las dos caras de la moneda."

(Francisco, 49 años, agente del CNP)

Su identidad profesional se apoya sobre ciertos saberes especializados incorporados en las oposiciones y las academias que dan acceso al puesto, pero además, y esto es lo más llamativo, los agentes cuentan con el margen de autonomía suficiente para incorporar la visión del mundo moral adquirida en su proceso de socialización barrial. Sus saberes barriales se transforman en saberes profesionales.

En el juego de identificaciones y contra-identificaciones -propias de un proyecto civilizatorio disciplinario en el que la construcción de identidades resulta fundamental y dicotómica-, se producen respuestas muy distintas ante las personas con las que intervienen, que convierten a los agentes securitarios en figuras que otorgan o deniegan en su interacción la condición de ciudadanía. Así es como un policía que acudió a comunicar la orden de desahucio a una mujer "gitana" que vivía "de patada" (ocupación ilegal de una vivienda vacía) "se extralimitó" en sus funciones y transmitió con cierto espíritu de revancha:

"¿Te gustaría que viniera yo y echase la puerta de tu casa abajo y me quedase a vivir? Yo tengo que vivir con mi madre y tú quieres casa gratis."

(Agente de policía nacional, entre 25 y 30 años) ${ }^{29}$

Estar en el "lado bueno" frente al "lado malo", esto es, pagar la hipoteca al banco y respetar la propiedad privada y la ley, hace de estos proletarios securitarios "policias de las prácticas", esto es, agentes morales que no han abandonado el sentido original de la policía (Foucault, 2008; De Certeau, 2006) ${ }^{30}$.

Dado el origen de clase de los agentes, el Estado tradicionalmente ha tendido a generar diferencias entre ellos y el pueblo. Sin embargo, hoy en día, el obrerismo identitario 
de los policías no parece estar en disputa con los poderes, sino que más bien todo ocurre como si nuevos (y viejos) lazos identitario-ideológicos, fundamentalmente basados en elementos nacionalistas y xenófobos postcoloniales, generasen entre buena parte de ellos un sentimiento de comunión con un pueblo que se siente amenazado en la competencia por recursos escasos. Esto hace innecesaria su separación del cuerpo social "normalizado" de los barrios, lo cual se expresaba en una comisaría de policía de Carabanchel: una placa recordaba a los policías caídos en acto de servicio con el lema "Somos el pueblo. Trabajamos para el pueblo". Buena parte de los agentes ha encontrado un sentido a su trabajo más allá del salario y las condiciones laborales funcionariales. Su sensación de servicio al "pueblo español" se colma cada día en sus intervenciones, las cuales son aplaudidas en el complejo mediático. En medio de una discusión con unas "brigadistas vecinales" que observaban la existencia -o no- de controles de identidad racistas una noche en el metro de Oporto, un agente que fue cuestionado en su labor respondió: "Señorita, cómo que quién soy yo. ¡Yo represento al Estado es-pa-ñol!". Pronunciando "es-pa-ñol", en un tono de voz elevado, con el riego sanguíneo enrojeciendo su cara, enfatizando la palabra con la separación por sílabas y acompañando cada una de estas sílabas con golpecitos con su mano derecha sobre el escudo nacional que llevaba en la manga izquierda del uniforme, puede apreciarse su alta identificación con la labor que llevaba a cabo. Razón profesional y emoción van unidas, al construirse como una suerte de soldados en guerra. La camaradería interna, el trabajo en equipo (aunque jerarquizado), el necesario imaginario de que "representan" a todo un pueblo que les apoya y el logro de la identificación de un enemigo -en ese caso, el "inmigrante"-, generan un fuerte sentido y motivación por su trabajo ${ }^{31}$. Este "obrerismo conservador", con amplia repercusión entre la población de barrios como Carabanchel, es el caldo de cultivo para la expansión de posiciones favorables al énfasis punitivo. Los policias de hoy en día se sienten plenamente integrados en la comunidad.

En contacto con desastres, violencia y conflictos en su emergencia, la visión binaria víctimas vs. culpables es la herramienta cognoscitiva fundamental para valorar su experiencia. En esta división vemos operar nuevamente la cosmovisión disciplinaria que tiende a juzgar moralmente a los sujetos en función de una norma que establece $a$ priori lo correcto y lo que se desvía de ella. Esta visión de la realidad encaja, además, con la información simplificadora de los medios de comunicación, la cual -incuestionadaviene a reforzar su mirada. En una ocasión los vigilantes de seguridad suspendieron la conversación que mantenian cuando el canal de televisión de Metro de Madrid comenzó a verter por las pantallas de la estación una batería de noticias de sucesos referidos a bandas de atracadores del Este de Europa y víctimas de "trata de blancas". Otro vigilante de seguridad de un centro de servicios sociales, Felipe $^{32}$, no perdia la oportunidad, en cuanto me veía, de contarme las noticias más trágicas y sangrientas de un diario de noticias cortas (emergentes, sin contexto). Su conclusión, en muchas ocasiones, era que "cada vez está esto peor". Y es que esta visión del "mundo" es aplicada también al espacio en el que trabajan, el barrio. La idea de otro vigilante, Ramón, sobre el distrito, era que se trataba de "un barrio muy chungo". Así, la concepción de culpabilidad desborda al individuo y pasa a significar a todo un entorno. El barrio queda, de esta forma, constituido en un barrio culpable:

"Lo que oía (...) es que era uno de los barrios [Carabanchel] más chungos que había, que estaba lleno de gente muy violenta, de traficantes, y lo que menos pensaba es que había tanto gitano, asi que fijate."

(Ramón, 44 años, vigilante de seguridad)

Este vigilante no encontraba ningún comentario positivo para referirse a Carabanchel. Le parecía "sucio", simbolizando esta suciedad ausencia de orden, complejidad, dificultad para mantenerlo bajo control. Ramón proyectaba sobre el barrio su habitus profesional y su momento biográfico y laboral: Carabanchel era el sitio donde trabajaba y esto, en continuidad con esa visión en la que asociaba el barrio a la violencia, lo convertía en un espacio "chungo". Sus condiciones laborales precarias y la escasez de reconocimiento social de su profesión le hacian sentirse sobrerresponsabilizado en el control de su objeto de trabajo (en este caso un edificio público). No parecía el único: en un foro para opositores de Internet, en el que un agente consultaba qué destinos eran aceptables a la hora de comenzar a hacer prácticas, otro más veterano respondía:

"TETUAN-LATINA-CARABANCHEL. Si por un nexo están unidos estos tres distritos, es por los problemas de convivencia que está generando la inmigración, que no hacen más que 
reproducir los esquemas ya señalados de bandas juveniles latinas, reyertas $y$, en el caso de Carabanchel, un alto índice de asesinatos con respecto al resto de distritos. En el caso de Latina, en la zona de Empalme, se están sucediendo agresiones a vecinos por parte de grupos de sudamericanos que, sin mediar palabra, blanden armas blancas para intimidar." ${ }^{33}$

Podemos observar cómo la obsoleta representación del barrio culpable de Ramón ("chungo", generador en sí mismo de las desviaciones) se desliza en el anterior texto hacia un espacio (escenario neutro y desculpabilizado de los conflictos) en el que operan culpables diferenciados (ciertos segmentos de la población considerados de/en riesgo). Las metáforas bélicas representan al barrio. Un policía municipal del distrito daba su visión en un foro público "desde la infantería" ${ }^{34}$ para señalar, cuidando la corrección política de su lenguaje, que se identificaba con el desasosiego de los "ciudadanos madrileños que ya estaban", entendiendo por tales, los autóctonos de edad social adulta. Ante el discurso neoliberal sobre la riqueza de las diferencias, sostenía ${ }^{35}$ :

\begin{abstract}
"Todo eso está muy bien, pero la situación en los parques es insostenible (...). ¿Desde la infantería, qué soluciones podemos aportar a esta población inmigrante? Lo que percibimos en Carabanchel es que el ciudadano, pues inmigrante, a la hora de tratarle se trata como ciudadano, sin distinguir de dentro y de fuera (...). [Pero] Hay vecinos de los madrileños que ya estaban, que sienten que pierden espacio vital."
\end{abstract}

(Agente de Policia Municipal, entre 45 y 50 años)

El policía prosiguió indicando que la inmigración suponía un aumento de trabajo ${ }^{36}$. En una realidad social como la que perciben estos agentes, cada tipología de delito se asocia a una categoría de "culpable", de otro. Pérez aportaba ciertas metonimias que simplificaban en forma de rasgos étnicos y nacionales a los delincuentes:

"Los gitanos (...) acabaron haciéndose con el mercado de la droga, y ahora se están pegando con los colombianos, por la droga, ¿sabes? Y entonces pasaron a Pan Bendito, de ahí a Jauja, y las chabolas que había aquí, en lo que es el Alto de San Isidro. (...) Además que lo estoy viendo todos los dias, la mayoría de lo que se coge son todos... Ahora, también, lo hacen mucho, hay mucho, hay un aumento muy grande de sudamericanos (...). La mayoría son juveniles, la mayoría de los palos son chavalillos jóvenes, ha aumentado mucho la delin- cuencia juvenil, y en, lo, yo no soy racista (...), y son cada vez más jóvenes, desde los 12 o 13 años empiezan a meterse en el ambiente, es más, los van enseñando, los van enseñando unos a otros. (...) Hay más [inseguridad] porque ha subido el número de inmigrantes, yo no soy racista, eh, hay mucho que viene a trabajar, yo no tengo ningún problema con él, trabajan, se dedican a su trabajo, se van a su casa y tal, pero hay una serie de elementos que han venido, que ya vienen directamente, se organizan para robar pisos, para pegar sirlas en la calle, para atracar, o sea, que vienen ya a delinquir."

(Pérez, 50 años, agente del CNP)

"Vienen a trabajar, se dedican a su trabajo, se van a su casa": aquellos inmigrantes que cumplan con el estereotipo de "buen currante" bajo la ética del trabajo meritocrática están camino de asimilarse a "lo normal", de entrar a formar parte de la ciudadanía; pero aquellos que se visibilizan en actividades extralaborales, en el espacio público, y no se van a su casa cuando termina la jornada laboral o escolar, son los "elementos". En el paisaje dibujado por Pérez, el análisis del contexto que como gestor intermedio de la seguridad (subinspector) poseía gracias a "su experiencia" en el cuerpo, se detenía en "la droga" (como si en las sustancias habitase el mal) y en la etno-nacionalidad (esencias conductuales y tradiciones culturales trasladadas desde los países de origen y nunca generadas en el propio contexto) como causas sociales del conflicto ${ }^{37}$. Los conflictos sociales se presentan en su emergencia: esa es su materia prima profesional.

¿Pero cómo afrontar esa realidad catastrofista sin trabajar con el contexto, sino sólo con la emergencia? Desde su cosmovisión, la desviación se afronta con disciplina y autoritarismo. Los resultados vendrían a demostrar que la "mano dura" funciona. Pérez afirmaba cómo gracias a la labor de la comisaría en la que trabajaba, su equipo había conseguido reducir los conflictos relacionados con el tráfico de drogas, aunque el propio mérito en relación a "los menores" no es suficiente cuando "se amparan en la ley del menor y no se les puede meter caña como se debería"38. La supuesta impunidad genera inseguridad en la gente, según este policía: "la gente ven que roba y que al día siguiente de haberle detenido, está en la calle". Para acabar con la "impunidad" de los menores habría que endurecer las leyes y tendría que funcionar adecuadamente el sistema judicial ${ }^{39}$. Esta estrategia discursiva consiste en 
situarse, como policía, cerca de "la gente" ("ellos ven que nosotros trabajamos"). El agente afirmaba que la visión que la población del distrito tiene de ellos es muy positiva, y una muestra de ello era que "hay mucha colaboración ciudadana". Frente al supuesto exceso de libertades, se hace necesario recomponer la autoridad.

Pérez, policía veterano que se autoidentificaba discursivamente con un estilo "respetuoso" en contraposición a los "jóvenes prepotentes" (reconociendo que él había sido uno de ellos), exponía dramáticamente cómo es el guión que le orienta a la hora de intervenir. Con respeto (asimilando respeto a la fórmula "de usted") pero sin dudar y sin dar oportunidad a la negociación a la otra persona. Se trata de no aplicar antes de empezar los esquemas prejuiciosos que guian las intervenciones diferenciales y de tratar a todo el mundo por igual, como "personas". No obstante, su actuación ideal consiste en la firmeza, en imponerse "sin perder los papeles", esto es, sin abandonar el rol autoritario y experto, ni su posición jerárquica:

"Por muy delincuente que sea un señor, es una persona. Si tú le tratas como a una persona, aunque ese señor haya pegado un navajazo o haya pegado una sirla, y tú le hablas con respeto, y le haces ver que tú le vas respetar, ese señor se portará bien. Ahora, si vas poniéndote a su altura y encima, poniéndole tú debajo, ese tío se rebotará, y montará el follón (...). Hombre, si se te revuelca ya cambia, pero si tú de momento él ve que le tratas con educación, normalmente la gente no se rebota, a no ser que vayan un poco tomaditos, como dicen ahora por ahí, un poco colocaos, o tomaos de alcohol o colocaos de otra cosa, entonces ya, ya cambia."

(Pérez, 50 años, agente del CNP)

Pérez era un policía experimentado en la incorporación de la autoridad y sus viejos saberes habian madurado sin salirse del paradigma disciplinario (a pesar de que su puesto de cierta responsabilidad le conmine a socializarse en la gestión neoliberal de la seguridad formándose en "sociología", manejando estadísticas, "vendiendo" su gestión, etc.). La droga era el principal problema, y sin embargo, como ya hizo notar, el barrio tenía un nuevo objeto de intervención especial que se delataba en su discurso a través de quienes van "un poco tomaditos"40. El objeto de la intervención policial estaba cambiando.

\section{Controles de identidad en Carabanchel}

Carabanchel presenta la mejor encarnación material y simbólica del tránsito de la lógica disciplinaria a la lógica de gestión securitaria neoliberal. La vieja cárcel de Carabanchel -el panóptico perfecto del franco-fordismo español- fue derribada justo cuando sus muros de represión comenzaban a ser resignificados. En su lugar se ha levantado en los últimos años el Centro de Internamiento de Extranjeros (CIE). Este centro combina en su funcionamiento las estrategias de corrección y castigo -a modo de mensaje lanzado al exterior a la población migrante- con otras que se sitúan en el terreno de la mera gestión de poblaciones -control sobre el excedente poblacional (De Giorgi, 2006). Del mismo modo, esta prisión estetizada (Davis, 1992) resulta invisible como tal para los vecinos autóctonos (algunos lo han designado "Centro de Integración de Extranjeros"): al fin y al cabo, dentro de una gestión diferencial no son los receptores del mensaje. La vieja cárcel otorgaba identidad al barrio, bien como estigma o bien como emblema, pero el nuevo dispositivo de encierro no es reconocido ni como tal ni como de Carabanchel ("de extranjeros" y "de Aluche") (García, 2011) ${ }^{41}$.

En sintonía con este tránsito, Carabanchel ha pasado de ser imaginado como un barrio culpable -imagen predominante del barrio obrero fordista pegado a una cárcel y, como tal, asociado a la delincuencia, al "lado malo"- a ser representado como un barrio víctima -escenario neutro sobre el que aplicar políticas securitarias diferenciales sobre aquellos sujetos de riesgo (por ejemplo el extranjero inmigrante) que amenazan al vecindario ("ciudadanos de bien")-.

En este contexto, los espacios públicos del distrito son objeto continuo de los controles de identidad que efectúa la policía en busca de personas "sin papeles" y en los que se materializan las dos lógicas desarrolladas, la de las políticas de gestión securitaria de poblaciones, por un lado, y la de la cultura profesional disciplinaria, por otro. Una enorme cantidad de recursos policiales se han destinado a las tareas de control identitario en busca de personas sin papeles, aplicando una sintesis de sendas técnicas descritas para la gestión securitaria ${ }^{42}$ : la diferenciación -basada en apariencias fenotípicas y estéticas- y la prevención -anticipándose a los conflictos (o más bien produciéndolos en el imaginario)-. Estos controles no responden a la bús- 
queda de delincuentes cuyas acciones causen alarma social y se aplican de forma discriminatoria según las apariencias de los cuerpos que transitan o permanecen en la vía pública, motivo por el cual están siendo denunciados como ilegales e ilegítimos por diversas organizaciones (BVODH, 2011). Su objetivo no consiste tanto en la expulsión de las personas extranjeras (una de las justificaciones populistas que se emplean) como en su control demográfico y social ${ }^{43}$ de cara a un control más general de la población. Si nos centramos en su dimensión económica, los costes de esta política para el Estado son muy elevados, si bien en términos de lógica económica neoliberal (socialización de los costes y privatización de los beneficios), el efecto es beneficioso para el mercado privado de trabajo ${ }^{44}$. Por otro lado, si atendemos a una lógica de control político, la identificación de las personas que se encuentran en el territorio (uno de los propósitos mínimos de todo Estado) y la prevención de la disrupción del orden socio-moral, son los criterios lógicos que orientan esta (bio)política ${ }^{45}$. Estos controles permiten, en materia de "seguridad ciudadana", recordar a una parte de la población, la que se siente extranjera, que su libertad de movimiento es condicional y que es objeto de una mirada especial, algo que a su vez tiene efectos disciplinarios sobre sus cuerpos (que tienen que condicionar muchas de sus prácticas cotidianas: itinerarios, ocio, sociabilidad, expresividad en el espacio público, relaciones vecinales, resolución de conflictos, etc.). Las identificaciones en la vía pública producen una alta proporción entre las detenciones que efectúa la policía, pese a que no tener "papeles" sea una simple falta administrativa (equivalente a una multa de tráfico).

La cultura profesional disciplinaria desfasada de los policías recobra su sentido para facilitar el objetivo primordial: en la interacción directa, el dispositivo securitario se hace carne y logra transmitir intercorporalmente la relación de poder. La diferenciación por orígenes nacionales y por fenotipos racializados y enclasados orienta la práctica policial hasta el punto de ser el elemento principal de identificación de una persona junto con el "sexo". Los discursos de los agentes a la hora de justificar estos controles indican cierta asunción de la lógica de gestión que estetiza la práctica policial de cara a minimizar los costes políticos, variando entre la toma de distancia con respecto a las decisiones ("Cumplimos órdenes"; "Estamos trabajando"), la eufemización de la práctica ("Es un control rutinario"), el camuflaje de su carácter discrimi- natorio ("No son racistas: paramos tanto a negros como a rumanos") o la plena explicitación de la tarea ("Es un control de extranjería") (BVODH, 2011), si bien cuando se profundiza en las conversaciones y aumenta la tensión a la hora de justificar su labor, aparecen elementos "menos profesionales" en su discurso. A partir de lo observado, parece generalizada la identificación con la labor por debajo del uniforme ("Si tú tienes cinco millones de extranjeros que no están pagando impuestos y les tienes que pagar educación, sanidad..."; "Aquí tienen que respetar las leyes. Cuando un español va a Marruecos le tratan mal y aquí los marroquies viven de puta madre. ¿Crees que eso es justo? Que se jodan y se vayan a su puto país"). Mientras que la lógica de la gestión securitaria no parte de un proyecto civilizatorio esencialmente racista, sino de un imaginario liberal basado en la libertad individual, en la competencia y en la naturalidad de las diferencias, su puesta en práctica parece requerir de una diferenciación jerarquizada en el seno del cuerpo social -cristalizada en un gradiente de derechos como trabajadores y ciudadanos- que instrumentaliza a otro proyecto ideológico más arcaico, pero en vigor, el de la cultura disciplinaria de los agentes, el cual parte de la existencia de una "bondadnormalidad" amenazada hoy por la alteridad con rostro de "extranjero".

Esta política tiene un carácter preventivo en la reproducción de un orden social. La estigmatización de la población extranjera al tener de manera recurrente parejas de policías a su lado -identificando performativamente a través de esa escena inmigración y delincuencia en el imaginario- no es sino una suerte de culpabilización simbólica que sitúa en el espacio de riesgo, el de los "culpables", a muchos vecinos de la ciudad. Este marcaje evita que muchas personas extranjeras se sientan "con derecho a" efectuar prácticas de visibilización y expresividad en el espacio público, sean éstas ilegales o no ("¿Bajar al parque? Es una locura"). La innovación, la expresión pública de prácticas no normales o que transgreden un cierto orden moral, resulta más costosa en aquellas personas o grupos que portan una culpa de partida que prácticamente les obliga a pedir permiso por usar el espacio común. Una joven boliviana expresaba la diferencia incorporada entre el primer control que sufrió a los pocos días de estar en Madrid ("les contesté que quiénes eran ellos para pedirme el pasaporte") y el último ("me temblaban las piernas y me quedé callada"). No se previenen delitos, 
pero sí transgresiones socio-culturales que pueden poner en riesgo cierto orden.

Sin embargo, los efectos de los controles de identidad en el espacio común no recaen únicamente sobre las personas migradas, sino sobre el conjunto de la población. Una de las consecuencias más relevantes de los controles de identidad es la diferenciación que contribuyen a construir. Dichos controles -así como el CIE- son invisibles para la mayor parte de la población de origen autóctono, mientras que constituyen una realidad cotidiana que condiciona prácticas e imaginarios entre muchas personas de origen extranjero. Esta diferenciación crucial en la vivencia de las fuerzas de seguridad y en la consideración del espacio público refuerza las fronteras necesarias para romper las posibilidades de vínculo vecinal. "Los españoles", "los gitanos", "los inmigrantes", y dentro de "los inmigrantes", los "rumanos", "los marroquies", "los sudamericanos"... El cuerpo vecinal del barrio queda atravesado por fronteras identitarias que finalmente conforman un espacio social fragmentado, algo que lo convierte en un objeto manejable de gestión. El espacio público pierde así una de las cualidades que lo caracterizarían, la posibilidad de camuflaje del anonimato (Delgado, 2007), y los espacios de uso comunitario se topan continuamente con barreras simbólicas que impiden imaginar lo común.

No obstante, los efectos de dominación de estas técnicas de "seguridad ciudadana" no son completos y están produciendo resistencias tácticas cotidianas por parte de las personas afectadas -desde burlar a los policías en los itinerarios a simular una menstruación sobrevenida que incomode la actuación de masculinidad del policía de turno- y estrategias diversas por parte de algunas organizaciones sociales - desde la elaboración detallada de formas de fuga y de redes sociales que contrarresten los check points y disuelvan los efectos de la técnica de la diferenciación a la "vigilancia a los vigilantes" que realizan las Brigadas Vecinales de Observación de DD.HH., invirtiendo el sentido de la técnica de la prevención situacional y del propio control social.

\section{NOTAS}

1 Uso postcolonial en el sentido de espacio social gestado en las metrópolis occidentales contemporáneas a partir de la llegada de población migrante procedente de las viejas colonias de la periferia del planeta. Las relaciones postcoloniales vendrían a complejizar la gestión de lo social al añadir, en el corazón de la propia metrópoli, el componente "racial-nacional" a las jerarquias de clase y de género.

2 Los profesionales de la seguridad aludidos en los dos primeros epígrafes del presente artículo, pertenecen tanto a cuerpos públicos como privados de seguridad, mientras que los aludidos en el apartado dedicado a los controles de identidad pertenecen exclusivamente al Cuerpo Nacional de Policía. Si bien existen enormes diferencias entre unos perfiles pro- fesionales y otros (incluso entre los profesionales de los distintos cuerpos de policía o en el seno de las distintas empresas de seguridad podremos encontrar matices que des-homogeneizan su cultura profesional), la investigación de la que parte el presente escrito analiza el funcionamiento de dispositivo securitario en un entorno concreto y no se centra exclusivamente en la policia, lo cual justifica la introducción de la agencialidad de todos los profesionales implicados (vigilantes y demás profesionales relacionados de un modo $u$ otro con tareas securitarias).

3 Esta condición de víctima como prerrequisito para el reconocimiento social como ciudadano, encuentra su correlato en la insistencia en la condición de víctimas (del terrorismo o de las acciones de "exaltados") 0 de héroes de los miembros de las
Aceptado: 15 de diciembre de 2011 
fuerzas de seguridad en el complejo mediático. El terrorismo fue durante unos años la fuente de legitimidad que permitía situar a las fuerzas de seguridad en una posición discursiva de mártires, lo cual permite establecer una alianza simbólica con muchas personas exentas de ser calificadas como sospechosas al no pertenecer a las categorías sociales criminalizadas.

4 Roberto había pasado por las filas del ejército (estuvo destinado como casco azul en la guerra de los Balcanes "defendiendo a los musulmanes", según sus propias palabras) y habia intentado ingresar, sin éxito, en la Policia Municipal de Madrid, cuerpo en el que había trabajado durante décadas su padre. En el momento de la entrevista era uno de los responsables de la seguridad privada de un "centro de menores" sito dentro de los terrenos de la propia cárcel de Carabanchel.

5 Según el entonces Ministro del Interior, Alfredo Pérez Rubalcaba, en el mes de mayo de 2010 sólo en la Comunidad de Madrid ejercian 11.346 agentes del Cuerpo Nacional de Policía, un 46\% más que en 2003 (http:// www.adn.es/local/madrid/20100330/ NWS-1417-Policia-Madrid-plantillaciento-crece.html, 30/03/2010). Entre los años 2003 y 2007, la ciudad de Madrid pasó de 5.632 policías nacionales a tener 7.235 (aunque otras fuentes de prensa hablan de una plantilla cercana a los 9.000 policías actualmente). Al mismo tiempo, la plantilla de policias municipales de la ciudad es de otros 7.000 efectivos, habiéndose incrementado en un 25\% desde 2003 a 2009 (nota de prensa del Ayuntamiento de Madrid del 2406-2009: http://www.munimadrid.es/ portal/site/munimadrid/menuitem.1 16d686253124a44c72f26e69fc08a 0c/?vgn36c948112210VgnVCM200 0000c205a0aRCRD\&tvgnextchanne I=6091317d3d2a7010VgnVCM 1000 00dc0ca8c0RCRD\&tvgnextfmt $=\mathrm{pda}$, 21/10/2009).

A este incremento de los efectivos de los cuerpos de seguridad públi$\cos$, hay que sumarle el fuerte crecimiento de vigilantes de seguridad privada vivida en los últimos años (superando los 27.000 efectivos a finales de 2008 en toda la Comunidad de Madrid) (http://www.adn.es/local/ madrid/20090429/NWS-2423-Policia-vigilantes-arriesgar-seguridadhomenajea.html, 21/10/2009).

6 En España, según los datos del Ministerio del Interior (19-09-2009), es de 47,6 infracciones penales por cada 1.000 habitantes, muy inferiores a las de países como Suecia $(120,4)$ o Reino Unido $(101,6)$. Los datos referidos a la Comunidad de Madrid indican que dicha tasa es de 69,2, similar a la media de la Unión Europea (http:// www.mir.es/DGRIS/Notas_Prensa/ Ministerio_Interior/2009/np031706. html, 23/10/2009). No ha resultado posible el acceso a la información desglosada por distritos que maneja el CNP.

7 Probablemente, entre los gestores políticos, se manejen estadísticas sensiblemente distintas a las que se publican.

8 Algunos colectivos que denuncian la continua criminalización de la inmigración coinciden en señalar que tras las relativamente altas tasas de detenidos y encarcelados extranjeros se encuentra un trato marcadamente diferencial al que recibe la población autóctona. Un ejemplo de este trato diferencial se produce cuando un juez criminaliza la pobreza al dictar prisión preventiva para una perso- na extranjera con escasos recursos, deduciendo que estos bajos recursos producirán en el futuro nuevos actos delictivos, mientras que los mayores capitales mostrables por alguien autóctono le salvarán con mucha mayor probabilidad de la prisión hasta la Ilegada del juicio. El resultado será el sesgo en la proporción de población extranjera en las prisiones y la retroalimentación del circuito cárcelestigmatización-delincuencia.

9 La percepción social de que la inmigración ha incrementado la inseguridad ciudadana no se corresponde con la realidad: entre 2002 y 2006 la inmigración creció en un 86\%, mientras el número de delitos por habitante descendió en un 22,7\% (CEDEHU, 2008).

10 El volumen de negocio en la Comunidad de Madrid de las empresas de seguridad privada ronda los $1.000 \mathrm{mi}-$ llones de euros de facturación anual (Diario adn.es: http://www.adn.es/local/ madrid/20090429/NWS-2423-Policia-vigilantes-arriesgar-seguridadhomenajea.html, 21/10/2009).

11 Si hay un sector económico dinámico en los últimos 30 años en España, este es el de la seguridad privada. Tal y como han analizado Torrente et al. (2005), en España las empresas privadas de seguridad se han insertado perfectamente en un nuevo modelo de gestión securitaria más centrado en la regulación que en la provisión. Las empresas venden, sobre todo, prevención situacional a otras corporaciones (incluido el propio Estado) como un servicio más que abarata costes (al evitar robos, vandalismo, etc.) o aumenta el margen de beneficios. Sin embargo, sin estar dedicadas, generalmente, a tareas de seguridad ciudadana en España (el monopolio de la fuerza física está en 
manos del Estado), estas empresas participan indirectamente en esta labor al estar sus empleados de cara al público. Estos autores hablan de un enraizamiento en España de un sistema mixto de seguridad. Es en ese contexto en el que buena parte de los hombres de la clase trabajadora (y cada vez más mujeres) trabajan en seguridad privada en condiciones muy precarizadas.

12 La estadística constituye una pantalla simbólica mediante la cual los cuerpos se transforman en números, constituyendo una forma de descorporeizar las relaciones sociales $y_{\text {, en }}$ este caso, la violencia.

13 Esta codificación de datos se realiza de manera competitiva entre las distintas dependencias, ya que el reconocimiento de las instancias superiores se efectuará sobre la base estadistica.

14 El Sindicato Unificado de Policía (SUP) ha denunciado cómo se somete a los agentes a una presión continua con la política de cupos que establece que cada comisaría de Madrid del Cuerpo Nacional de Policía (CNP) debe efectuar semanalmente un número de identificaciones y detenciones basados en la nacionalidad de las personas ("15 bolivianos, 12 ecuatorianos", etc.). Evidentemente, la forma de producir estos datos, es decir, de llegar a las cifras de gestión finales, no será pública (en este caso el SUP visibilizó este hecho como forma de presión en el marco de sus reivindicaciones laborales), pero los resultados finales sí lo serán en una eventual competición electoral para mostrar qué partido es más "antiinmigración". Además de contribuir a la redistribución de los riesgos gestionando la realidad de este modo (interviniendo sobre poblaciones, como "los bolivianos", y no sobre delincuentes probados), se consigue llegar a unas cifras finales que sí serán presentables a la opinión pública (como el número de expulsiones de extranjeros, de denuncias resueltas, de detenidos, etc.).

15 http://www.elmundo.es/elmundo/2005/12/23/madrid/1135339490. html (24/11/2009).

16 Programa coordinado por Bárbara Scandroglio y Jorge S. López, profesores del Departamento de Psicología Social y Metodología de la Facultad de Psicología de la Universidad Autónoma de Madrid. La información que aquí presento procede de la nota de prensa que sendos responsables hicieron circular por Internet.

17 Además, la nueva intervención no se basaba en ningún acto delictivo reciente y criminalizaba a todos los asistentes a una reunión sin que pudiese probarse delito alguno.

18 La lógica del emergencialismo consiste en el uso de los acontecimientos mediante la generación de alarma a través de los medios de comunicación para legitimar decisiones encaminadas a la restricción de derechos y libertades, el incremento de plantillas policiales, la implementación de planes especiales, etc.: el acontecimiento que las dio lugar se retira, pero las medidas excepcionales que se crearon para afrontarlo continúan (Grupo de trabajo sobre inmigración y racismo de la IAP de Lavapiés, 2002). Si se interrumpen procesos de intervención iniciados, echando por tierra el trabajo de dos años, poco importa, ya que el objetivo es la capitalización de las intervenciones desde arriba y el mantenimiento dentro de unos límites tolerables del problema, algo conseguido con unas y otras medidas de manera combinada.
19 Tuve la oportunidad de entrevistar a Pérez en dos ocasiones a lo largo de 2005: una, en unos billares que eligió él y en los que alternó su confianza en el entorno (conocía a buena parte de los que alli estaban) con un exhaustivo control de la situación (evitando estar de espaldas a la puerta para controlar quién entraba, por ejemplo). De 50 años de edad, Pérez habia crecido en el Carabanchel fordista y ahora ejercía en el distrito con un cargo intermedio. Ya no hacía apenas trabajo de calle, sino de organización. Se había formado en los últimos años para ir ascendiendo y en los cursos había descubierto ciertos vínculos entre estructura social, droga y delincuencia que no cesaba de citar.

20 Pérez se refería al trabajo de su equipo en Carabanchel, atribuyendo los problemas de bandas de jóvenes de origen latinoamericano a otras zonas de la ciudad, a otras comisarías. En el imaginario de la gestión, el mundo está dividido en fronteras rígidas, por lo que si un apuñalamiento se produce en otro distrito de la ciudad (aunque sea a escasos metros del propio), no es un problema, de ahí que se cree la ilusión condensada en la frase "lo tenemos todo controlado": el control policial, pese a los dispositivos preventivos de seguridad, no tiene más remedio que ir detrás de los acontecimientos, de ahí que mientras un hecho no ocurra en el suelo administrado (y sobre todo, no tenga repercusión mediática), no comienza a ser un problema.

21 Aunque reconocía que los robos con fuerza habian disminuido, al igual que los producidos sobre locales. Llama la atención, además, cómo en la construcción de estos datos se incurría en contradicciones poco creibles que, 0 
bien indicaban el puro invento de las cifras o disfrazaban las intervenciones más "feas" para transformarlas en "bonitas" o legítimas: así es como refería que los "robos a domicilio" habían disminuido mientras que, sin embargo, habían detenido a "un 41\% más" de sus autores. Detener no significa capturar a los culpables, sino llevar a comisaria y privar de libertad a sospechosos, y es probable que los controles de identidad a las personas extranjeras, en situación de indefensión jurídica, estuvieran sirviendo para disparar las cifras de eficacia del CNP en muchos ámbitos.

22 Estas instituciones saben adaptar a cada realidad local una determinada política de imagen. Así es como en barrios como Lavapiés, caracterizado por una buena proporción de población migrante, por la presencia de muchos jóvenes "alternativos", y al mismo tiempo señalado por un sector ideológico como inseguro, la forma de legitimarse ante el vecindario se realiza por medio de un refinado "Programa comunitario de seguridad ciudadana" Ilamado "Seguridad en diversidad" (Iniciativa cofinanciada por el Programa de Prevención y lucha contra el Crimen de la Dirección General de Justicia, Libertad y Seguridad de la Comisión Europea).

23 El Ministerio del Interior anunciaba en marzo de 2010 la elaboración de un decreto para dar prioridad a los deportistas profesionales en las pruebas de acceso al Cuerpo Nacional de Policía y a la Guardia Civil. Con el fin de mejorar la eficacia policial, declaraba el decreto, se trata de enriquecer la plantilla con "efectivos dotados de un componente físico y de sacrificio personal al más alto nivel, produciéndose una sinergia entre el fomento del deporte y la mejora de los recursos humanos de las Fuerzas y Cuerpos de Seguridad del Estado" (Diario "Público" del día 18/03/2010: http://www.publico.es/ deportes/302018/rubalcaba/ficha/ deportistas, acceso: 18/03/2010).

24 La cultura disciplinaria descrita por Foucault $(2002,2007 b)$ se caracterizaba por su énfasis en la anatomopolítica: los cuerpos, dotados de las categorias de sujeto correspondientes, experimentaban una serie de transformaciones (procesos de subjetivación) como resultado de los cuales surgían los individuos. Estos individuos, que interiorizan dichas categorias de sujeto y que cobran conciencia de sí mismos, obedecen a los mandatos identitarios y a los procesos de disciplinamiento vigilados por la mirada panóptica de las diseminadas y capilares figuras de poder, al mismo tiempo que se convierten en agentes activos de (auto) vigilancia. Esta cultura disciplinaria y autoritaria característica de la modernidad, cuyos fines eran tanto económicos (productividad) como políticos (docilidad), tuvo su máxima expresión durante la sociedad de producción fordista. Los valores meritocráticos penetraron entre las clases populares, quienes al mismo tiempo que ejercian la resistencia, se apropiaban de los mecanismos de disciplinamiento y de las formas de diferenciación identitaria.

25 Entre los sectores populares desarticulados tras la reconversión industrial de las décadas de 1970 y 1980 comenzó a florecer un nuevo proletariado de los servicios, un servoproletariado (Rodríguez, 2007) que emplea a muchos de sus miembros en la seguridad.

26 Ramón, de 40 años de edad, era vigilante de seguridad privada en un
Centro de Servicios Sociales del distrito. Con estudios primarios y origen popular reúne ciertas cualidades sociales que le hacen una persona propicia para insertarse en este nicho laboral, uno de los más precarios para la fuerza de trabajo masculina.

27 Así, Javi hablaba de "romper el cueIlo", "dar un buen golpe", "cortar los brazos", "partir las piernas" o "dejar la cara como un tomate". Estas expresiones, que aluden casi siempre a partes del cuerpo, forman parte de una actuación estratégica de la masculinidad intimidatoria.

28 Comentarios recogidos durante sesiones de observación en las instalaciones del metro. Algunos de ellos son la respuesta a mi interpelación.

29 Reproducción aproximada efectuada por la persona afectada que vivía "de patada".

30 Frente a un modelo de gestión securitaria neoliberal, en el que se trata de prevenir situacionalmente el delito y redistribuir el riesgo, la mayor parte de los agentes siguen encarnando los valores de la sociedad disciplinaria, mucho más intolerante con las diferencias, orientados por una visión del mundo rígida y un modelo de intervención asimilacionista que trata de cambiar al otro (incivilizado) para que se normalice y sea "gente de bien". Ahora bien, esta distancia entre sendas lógicas -la disciplinaria, que predomina en lo profesional, y la neoliberal, que rige en la gestión securitaria-, se salva cuando ambas cooperan de forma superpuesta en las prácticas policiales cotidianas.

31 En el "Foro Policía", un foro de Internet para miembros de las fuerzas de seguridad, se verían comentarios frente a un grupo que denunciaba los controles de identidad con perfil fenotípico. "Vamos cantando cara el mañana, la alegría 
de ser español..." (escrito en colores de la bandera española) era una de las proclamas (http://www.foropolicia. es/foros/viewtopic.php?f=1\&t=59056, 02/02/2010).

32 Felipe, con 45 años de edad, procedía de un pueblo y era vigilante de seguridad. Al tiempo de trabajar con él, fue dado de baja -presumiblementepsiquiátrica.

33 http://www.buscaoposiciones.com/ foro/Oposiciones-Cuerpos-y-Fuerzasde-Seguridad-fmen-33-3182260. htm (04/03/2010). Casualmente, otro día encontré que esta descripción no era sino un "corta y pega" de otra noticia publicada en el diario conservador $A B C$ (http://www.abc.es/ hemeroteca/historico-12-08-2005/ abc/Madrid/los-diez-barrios-de-lalista-negra-_21128765256.html, 04/08/2011).

34 Jornada de sensibilización sobre inmigración para funcionarios del Ayuntamiento de Madrid realizada en mayo de 2005.

35 En dicho foro, Tomás Vera, del ala liberal del partido gobernante, presentaba el "Plan de Inmigración del Ayuntamiento de Madrid". Este político dio una visión intercultural de la inmigración: "Madrid no está acabada", "en la medida en que se conoce la ciudad, se participa en ella...", "si dotas de igualdad, hay responsabilidad compartida, no hay objetos pasivos a los que cuidar", "el objetivo filosófico del plan es articular la convivencia en la ciudad". Posteriormente, el antropólogo Carlos Jiménez presentaba un panorama amable sobre la aportación de los inmigrantes a nivel económico, cultural...

36 Estas conclusiones resultan similares a las producidas por Daniel Wagman en el informe sobre el "perfil racial" en España (2005).
37 Algunas de las cadenas de correo electrónico que circulan entre miembros de las fuerzas de seguridad están estrechamente relacionadas con el esquema binario-disciplinario en el que existen culpables ("pedófilos", "violadores", "ladrones", "hackers que despeluchan las cuentas corrientes", etc.) y víctimas ("niños o menores", "mujeres", "ancianas", "ciudadanos", etc.).

38 Pérez titubeaba en su voz al hacer esta afirmación: creía que, quizás, estaba siendo políticamente incorrecto ante mí, un antropólogo que para él era sinónimo de periodista.

39 Las luchas de poder en el campo de la justicia entre grupos corporativos (magistrados, policias...), así como en el seno de la propia policía, son traducidos, en muchas ocasiones, en problemas sociales más generales, como el de la "inseguridad ciudadana". Remi Lenoir mostró como las diferencias de poder social entre jueces y policias, en función, sobre todo, de las diferencias en capital cultural y académico, han inducido a muchos comisarios a formarse y a exhibir propiedades sociales, culturales y escolares cercanas a las de los magistrados, como en el caso de este informante (Lenoir, 1999).

40 La expresión "ir tomado" se usa en algunos países latinoamericanos para significar el estado de embriaguez.

41 Recientemente y persiguiendo nuevamente el camuflaje de la actividad de dicho Centro, el Ministerio del Interior ha renombrado este dispositivo como Centro de Estancia Controlada de Extranjería (CECE).

42 Las Brigadas Vecinales de Observación de Derechos Humanos (BVODH), un colectivo de vecinos y vecinas que ha tratado de recopilar información sobre los controles de identidad, ha consta- tado dichos controles en el $42 \%$ de sus 113 "salidas" por la ciudad de Madrid entre el 10/12/2009 y el 10/05/2011 (24 de las cuales se efectuaron en el distrito de Carabanchel) (BVODH, 2011). Teniendo en cuenta las limitaciones horarias de dichas brigadas no profesionales y la aleatoriedad de los encuentros con la policía efectuando esa labor, podemos concluir que se trata de una práctica sistemática.

43 Instrucciones como la Circular 1/2010 de la Comisaría general de Extranjería y Fronteras han sido denunciadas por distintas organizaciones, entre ellas el Sindicato Unificado de Policía. Éste mismo sindicato señalaba que en 2009 se habian producido en Madrid 445.000 identificaciones y 22.000 detenciones (http://www. elmundo.es/elmundo/2010/02/09/espana/1265725220.html, 10/02/2010). De esas 22.000 detenciones, que se producen por una falta administrativa -no tener residencia legal en España-, y no por la comisión de un delito punible, se expulsa a una mínima parte (cada expulsión tiene un coste aproximado de 5.000 euros).

44 A nivel demográfico se controla una masa de población que, así, se mantiene dentro de unos márgenes razonables: el mercado de trabajo requiere personas sin papeles que "tiren" hacia abajo del resto de los salarios. Frente a la supuesta libre venta de la fuerza de trabajo en el mercado laboral que caracterizaría al capitalismo como modo de producción Sandro Mezzadra (2009) ha puesto el énfasis en el embridamiento que supone la nacionalidad para regular dicho movimiento desde el Estado $y_{1}$ en último término, para establecer diferencias en el valor de dicha fuerza de trabajo. Al mismo tiempo, un exceso de personas sin papeles podría 
desestabilizar el orden económico al restar poder a ciertos sectores que explotan trabajo legalmente (por el surgimiento de mercados informales), de ahí que se requiera mantener entre unos límites inferiores y superiores el número de personas "ilegales" a través del control de flujos y de las actuaciones de la policía en materia de extranjería.

45 El cálculo político en la labor policial, aunque abstracto, resulta tan relevante como el económico. Diego Palacios (2007) ha analizado la progresiva adopción de prácticas policiales antidisturbios de carácter no letal como tecnología de gobierno que se fue extendiendo a partir de 1820 desde Inglaterra al resto de paises europeos y EEUU. La tesis de Palacios se apoya en el cálculo del coste en términos políticos en las democracias parlamentarias occidentales.

\section{BIBLIOGRAFÍA}

Ávila, D. y M. Malo (2007): “¿Quién puede habitar la ciudad? Fronteras, gobierno y transnacionalidad en los barrios de Lavapiés y San Cristóbal", en Observatorio Metropolitano: Madrid ¿La suma de todos? Globalización, territorio, desigualdad, Madrid, Traficantes de Sueños, 505-632.

Baratta, A. (2001): Seguridad. Capitulo Criminológico. 29(2): 1-24.

Bauman, Z. (2003): Trabajo, consumismo y nuevos pobres, Barcelona, Gedisa.

Brigadas Vecinales de Observación de Derechos Humanos (BVODH, 2011): Controles de identidad racistas en Madrid. Informe de las Brigadas Ve- cinales de Observación de los Derechos Humanos (2010/2011). En línea: http://www.gugms.net/brigadasddhh/ INFORME_BRIGADAS_2011.pdf, Madrid (01/08/2011).

Centro de Defensa y Estudio de los Derechos Humanos (CEDEHU, 2008): Racismo institucional y racismo social. En línea: http://centrodefensaestudioderechoshumanos.blogspot.com/2008/08/ racismo-institucional-y-racismo-social.html (04/03/2012).

Davis, M. (1992): City of Quartz. Excavating the future in Los Angeles, Nueva York Vintage.

De Certeau, M. (2006): La escritura de la historia, México D.F., UIA-ITESO.

De Giorgi, A. (2006): El gobierno de la excedencia, Madrid, Traficantes de sueños.

Delgado, M. (2007): Sociedades movedizas. Pasos hacia una antropología de las calles, Barcelona, Anagrama.

Foucault, M. (2002): Vigilar y castigar. Nacimiento de la prisión, Buenos Aires, Siglo XXI.

Foucault, M. (2007a): Nacimiento de la biopolítica, México D.F., FCE.

Foucault, M. (2007b): El poder psiquiátrico, México D.F., FCE.

Foucault, M. (2008): Seguridad, territorio, población, Madrid, Akal.

Garcia, S. (2011): "Estetización urbana y dispositivo securitario: encarnaciones carabancheleras", Actas del XII Congreso de la FAAEE, León.

Grupo de trabajo sobre inmigración y racismo de la IAP de Lavapiés (2002): Inmigración, emergencia, seguridad, Contrapoder n. ${ }^{\circ}$ 6; Flujos migratorios: éxodo y ciudadanía global, Madrid. http:// www.sindominio.net/contrapoder/article.php3?id_article=30 (21/04/2010).
Ibáñez, J. (1985): Del algoritmo al sujeto. Perspectivas de la investigación social, Madrid, Siglo XXI.

Lazzarato, M. (2008): Le Gouvernement des inegalités. Critique de l'insecurité néolibérale, París, Éditions Amsterdam.

Lenoir, R. (1999): "Desorden entre los agentes del orden", en Bourdieu, P. (ed., 1999 [1993]): La miseria del mundo, Madrid, Akal, 195-199.

Mezzadra, S. (2009): Derecho de fuga, Madrid, Traficantes de Sueños.

Palacios, D. (2007): "Botes de humo. Por un análisis histórico-político de la adopción de técnicas antidisturbios no letales". Comunicación presentada en el Congreso de la FES 2007, Barcelona.

Observatorio del Sistema Penal y los Derechos Humanos de la Universidad de Barcelona (OSPDH, 2005): "El populismo punitivo. Análisis de las reformas y contrareformas del Sistema Penal en España (1995-2005)", Quaderns de Barcelona. Ajuntament de Barcelona. Regidoria de Dona i Drets Civils, Barcelona.

Rodríguez, E. (2007): "Nuevos diagramas sociales. Renta, explotación y segregación en el Madrid global", en Observatorio Metropolitano (ed.): Madrid ¿La suma de todos? Globalización, territorio, desigualdad, Madrid, Traficantes de Sueños, 95-169.

Torrente, D.; Bosch, J. L. y Valencia, V. (2005): "Organizando la seguridad: análisis organizativo de los servicios privados de seguridad en España", Política y Sociedad, 42(3): 185-208.

Wagman, D. (2005): "Perfil racial en España: Investigaciones y recomendaciones", Open Society-Justice Iniciative, 1522. Documento en línea: http://www. gea21.com/_media/publicaciones/perfil_racial_en_espana.pdf, 02/11/2010. 